\title{
The Lognormal Distribution of the Age gaining Great Achievement of the Talents in Humanities \& Social Sciences
}

\author{
Lu Cui \\ Shuhua Zhong \\ College of Public Administration, Huazhong University of Science and Technology, \\ 1037 Luoyu Road, Hongshan district, Wuhan, China \\ Corresponding author: hustercui@gmail.com
}

Doi:10.5901/mjss.2013.v4n9p293

\begin{abstract}
Though each individual has special growth contrail in the community of humanities \& social scientists, they also have common stage-figures in the process of growth. Age is the natural property and obvious objective characteristic of human; it also makes an important reference for grading stage. The analysis of age gaining magnificent achievement of humanities \& social scientists from the fifteenth to 1990s suggests that, the achievement ages of humanities \& social scientist get lognormal distribution and the peak age is 41 , from 15th century to 20 th century the peak age tend to forward in the whole, and talent productivity of every age level keep balance there no achievement concentrate on one level in the field of humanities \& social sciences.
\end{abstract}

Keywords: Humanities \& Social sciences; Great Achievement;Age; the Lognormal Distribution

\section{Introduction}

Though each individual has special growth contrail in the community of humanities \& social sciences, they also have common stage characteristics in the process of growth. Age is the natural property and an obvious objective characteristic of human beings, it also makes an important reference for grading stage.( Wu Peng-sen\&Fang Lieshu2011) Beard in 1874 firstly started to research the relationship between age and achievement, he collected materials from various celebrity biographies and figured out the age average while scholars achieved their great masterpieces; he also had described relation curve of age and achievement productivity, a single peak curve whose peak is forty years old. (George M. Beard 1874)By further econometric study in 1881 Beard proposed Beard's Law: 70 percent of academic achievements created by scholars under 45 and 80 percent created by scholars under 50.( George M. Beard 1881)But his research not gained people's attention, scholars began to concern the question of age and achievement until Lehman published "Age and Achievement". Through studying on age and achievement of humanities \& social scientists gets different forms of age curve, generally there are three types:

First is single-peak age curve, which productivity increases with years to a peak, then shows a downward trend, epitomized as inverted U - shape. Harvey C. Lehman(Harvey C. Lehman 1956), Stephen Cole(Stephen Cole 1979), Sharon M. Oster and Daniel S. Hamermesh(Sharon M. Oster 1998) believed economics was the young's game, achievements mainly focused on 36 to 50 years old. Hendrik P.van Dalen thought great masterpieces of the winner of Nobel Prize on economy almost being created on his golden age period: from 29 to 38. (Hendrik P.Van Dalen 1999) David W.Galenson and Bruce A.Weinberg measured the age curve of Nobel Prize winners by quotation ratio of all achievements in one year, and found the peak age of "theory economists" is 43 years old, however experienced economists is 61 years old.( David W.Galenson 2005)Svein Kyvik adopted horizontal data that gained through grouping scholars by age and discovered the most productive is 40-44 group in the field of humanities and natural sciences; the productivities in social sciences kept stable but in humanities field the productivities of 55-59 group tended to decrease. (Svein Kyvik 1990)Otherwise, by studying cases Dean K.Simonton concluded: inverted-J shape theory, different from inverted-U, would down as productivities get the summit with years, yet not down to original academic level.( Dean K.Simonton,1977)

Second is bimodal curve, there is two peaks in the age curve. Bimodal curve could be divided into two shapes: one, age curve downing after the second peak. This shape of saddle Alan E. Bayer and Jeffrey E. Dutton proved in the 
field of psychology, economics and social sciences through making varied model assumptions. ( Alan E. Bayer\&Jeffrey E. Dutton) Thomas H. Goodwin pointed out productivity distributes on the double-hump shape in the life-cycle as he had cased 140 tenured professorships of economics.( Thomas H. Goodwin,1995)The other, second peak appears in the end of scholar's lifetime. For example, Dean K. Simonton researched 172 classical composers to discover the last achievement phenomenon, which achievement was created in the end of composers' life. (Dean K.Simonton 1989)Dean K. Simonton pointed that creative productions gained at scholar's remaining life, especially as their life would end.( Dean K. Simonton 1991)

Third is linear relation, Dean K. Simonton inquired the trend of achievements change with age by the proportion of the excellent to all achievements based on ten cases of classical composers, he got a horizontal age curve. According to this curve, excellent achievements show a pattern of sustained and stable probability of success, not changing with years, the proportion it takes is a constant in all achievements. (Dean K.Simonton 1977)A.M. Diamond underlined whatever product quantity of outputs and quality of each paper or the both would decline with age from an economic perspective. (A.M.Diamond. Jr 1984)Hendrik P. van Dalen taking empirical research on Nobel Prize economists suggested outstanding economist's age contrail is different from the general; from the start, the outstanding economist's achievement was on the higher stage and kept the stage in the long time not down with age.(Hendrik P.Van Dalen 1999)

Researching on the relationship of age and achievement firstly originated from natural sciences and gained abundant research achievement. However correlation study on age and achievement of humanities \& social scientists started later, there are fewer materials. Nearly half a century, scholars had launched a heated dispute and given all kinds of guesses and descriptions toward achievement and age. But many papers indicated that there was been a blank space for overall description on the distribution of talent achievement age in humanities \& social sciences since 15th century. Obviously, it has important cognitive values for uncovering the whole features of the distribution of talent achievement age.

\section{Sample Selection and Data Source}

\subsection{Base for Sample Selection}

Age curve presents the trend of achievements alteration with age. The changing of age curve always being affected by many situations, Harvey C. Lehman concluded three situations: firstly, the type of achievement; secondly, the definition of excellent achievement; thirdly, the selection of measuring method.( Harvey C. Lehman 1956)There would form different shapes about age curve for different definitions on achievement and age in scholars' research conclusions.

\subsubsection{Time Range of Sample Selection}

Humanities \& social sciences was founded in about 14th and 15th century, at that time European ideological field gradually woke up from the Dark Ages and began to challenge the dominant theology. The ideological and cultural movement lasted from the middle of the 14th century to early 17th century, this period also being called Renaissance. In the 15-16th century, the Latin word "humanists" was used in Europe. At that time, social science was contained into humanities and this phenomenon lasted hundred of years. Until in the mid-later18th, subjects making empirical research on society via empirical method, such as century economics, sociology and politics etc. were separated from social sciences and gradually founded systemically their own theoretic structure in 19th century. (Wu Peng-sen\&Fang Lie-shu 2011)We can see that humanities \& social sciences flourished from the Renaissance period, so the time range of sample selection also is from 15 th century to late 20 th century in the paper.

\subsubsection{Life Figure of Sample}

Researches on humanities \& social sciences need the accumulation of knowledge and social experience, and scholars' great academic achievements especially could present the characteristic of well-grounded accumulation. (Zhou Da-ya 2004)Scholars maybe created great masterpiece as they are goanna die. For example, Charles McLean Andrews, an American historian who lived from 1863 to 1943, his representative work "The Colonial Period of American History" was written during 1934-1937 and was awarded the Pulitzer Prize for the first volume of the representative in 1935 as 72 years old. Charles McLean Andrews didn't finish the fourth volume until in the end of his life. Scholars are liable to create masterpieces before death because achievements creation in humanities \& social sciences has the characteristic of well- 
grounded accumulation, therefore the paper selects all samples of humanities \& social scientists dying before January 1 st 2013 so as to ensure the integration of samples selected.

\subsubsection{Definition of Achievement}

Dean K. Simonton had pointed that the shape of the relationship between age and achievement depending on how to define achievement. (Dean K.Simonton 1988) The paper takes the quality of literature as the standard of defining achievement here. Selecting great masterpieces whatever book or paper, only if it could give most social influence to society and most contribution to human civilization as representative work. This is achievement, which could be published books or papers, such as The Wealth of Nations of Adam Smith and Social Contract Theory of Jean-Jacques Rousseau. There are some scholars considering the quantity as the standard of judging achievements because the period of highly productive also is the period of easily creating masterpiece. (Dean K. Simonton 1991) But using the quantity as valuing standard would narrow the range of samples. Such as, according to the characteristic of wellgrounded accumulation in creating achievements of humanities \& social sciences, some scholars had accumulated for several decades prior to leaving a highly valuable work. There is no productive period and the scholar would be excluded from research field. Obviously, selection like that is impractical and artificially narrows the range of samples.

There is one special situation of judging achievement, that we cannot rank the value of each one while a scholar has given many excellent works. At that time we will choose the one firstly being famous and giving most influence as the representative. For example, Philip Henry Stanhope a British historian wrote many historical works in his life span, his works in 1829, 1832 and 1853 respectively is so significant that the posterity feel difficult to say which one is of most importance. Then we choose the earliest work The Life of Belisarius written in 1829 as the achievement.

\subsubsection{Age}

Age is a most important data in paper, here means scholar's achievement age. Usually achievement age is subject to published time of representative work, but if representative work just taking form of manuscript not published or published after the writer dying, we regard the finishing time of manuscript as age time. Such as German philosopher Arthur Schopenhauer was born in 1788, his representative work The World as Will and Representation was finished in 1818 and published in 1819, therefore Schopenhauer's achievement age is 31 year old.

Need to say, collection of age data has several special situations. Firstly, for multi-volume literature, if one of volumes gets great attention then the published time of the volume would be thought as achievement age. For example, American historian Charles McLean Andrews, was alive from 1863 to 1943, his representative work The Colonial Period of American History was written during 1934-1937. And he won the Pulitzer Prize with the first volume of it in 1935, thus his achievement age is 72 years old. Supposing no above situation, achievement age is the time of work completely finished and published. Secondly, some magnum-opuses need several decades to finish so that the author dies before completion and continue to be written by another. In this situation, we will take the first author's death age. Such as Barthold Georg Niebuhr, lived from 1776 to 1831, his representative work "Roman History" was completed in 1932 edited by Johannes Classen after his death. Thus his age data is 55 years old.

\subsubsection{Subject}

Researches in humanities \& social sciences possess strong individuality and uniqueness, and mostly focusing on the experience and the reflection of value and meaning of human-selves. (Ou Yang-kang 2004) It discusses the values, behaviors, goals and meanings of life mainly through the way of explanation and comprehension. (Yuan Xi-lin 2011) In other words, literature itself isn't science but the knowledge of researching on literal works is science. Social science takes human society including the social phenomenons of economy, politics and social activities as research object. Different institutions and organizations have their own criteria and systems for classification of social science. The paper refers to the definition of classification on humanities \& social sciences from Encyclopedia Britannica, The Main Current in Humanities \& Social Sciences published by UNESCO and Frascati Manual published by OECD. Here humanities \& social sciences contains 13 subjects: philosophy, history(history and the history of history subject ), archaeology, religion, linguistics, literature(all studies of literature, viz literary theory, literary criticism; not including literary creation: novel, poem and so on ), art(all studies of artistic works, viz art theory and art criticism; not including artistic creation such as painting and sculpture), politics, economy, sociology, psychology, law and anthropology. 
A scholar may study several subjects, for example, Abraham H. Maslow is both a psychologist and a philosopher. Generally we take the subject giving most influence as a Representative. Maslow is famous for self actualization theory, so he belongs to the field of sociology.

\subsection{Source of data}

The paper's data mainly come from Micropædia Britannica, and further to look up World Blue Book of Humanities \& Social Sciences. Moreover, the paper uses network resources of Google Scholar and Wikipedia to verify and add vague or unsafe information.

Encyclopedia Britannica has a worldwide reputation for making great contribution to human civilization progress, and has 200 years' history by regular update since published during 1768-1771. Encyclopedia Britannica known for strong academy and high authority, and it's the most familiar encyclopedia for China's intelligentsia. China signed an agreement with America on collaborating to translate and publish Chinese version of Micropædia in August 1980. America was in charge of offering the latest revising draft and pictures, the editors and translators of Chinese version are all specialists and scholars of Chinese academia.

Chinese version of Micropædia entirely complies with the original edition, just expurgating some explanatory articles and pictures. The paper only takes the information of name, date of birth and death, nationality, subject field, date of the representative being published, thus expurgation hardly makes an influence to the data collection.

Chinese version of Micropædia has been revised several times since published firstly in 1985, but its content does not change in essence. The paper chooses data from ten volumes of 1985 version and a supplementary volume of 1990, together 11 volumes, and gets 1391 samples.

\section{Statistical description on the distribution of general talents' achievement age in humanities \& social sciences}

According to physiology, a person's memory deteriorates but comprehension develops with age. The golden time of a person's creation is the period of best memory and quick comprehension. The talent in this period already has an amount of social practical experiences and is energetic, sensitive and creative; therefore, this period is the best time of making achievements.

\subsection{Analysis by descriptive Statistics on the distribution of talents' achievement age}

Table 1 shows the frequency of talents' outputs for all age groups in humanities \& social sciences, also meaning the number of acquiring great achievement in each age-group. The outputs of 41-50 group are the largest accounting for $31.09 \%$, followed by $31-40$ age group.

Table 1. Statistics of talent's output and age in humanities \& social sciences

\begin{tabular}{|c|c|c|c|c|c|}
\hline age group (year) & amounts & $\%$ & age group (year) & amounts & $\%$ \\
\hline Under 20 & 5 & 0.36 & $51-60$ & 231 & 16.61 \\
\hline $21-30$ & 136 & 9.78 & $61-70$ & 130 & 9.35 \\
\hline $31-40$ & 383 & 27.53 & $71-80$ & 62 & 4.46 \\
\hline $41-50$ & 428 & 30.77 & above 81 & 16 & 1.15 \\
\hline
\end{tabular}

There are 1391 available observations in table 2. For achievement age of talents in humanities \& social sciences: the oldest is 91 and the youngest is 16 , the Mean is 45.93 , Mode is 41 , Coefficient of skewness is 0.628 , Coefficient of kurtosis is 0.022 . The empirical frequency distribution of humanities \& social scientists' achievements has the characteristic of positive-skewed, leptokurtosis and fat-tail.

Table 2: Frequency description of talents' outputs in Humanities \& Social sciences

\begin{tabular}{|l|l|l|l|l|l|l|l|l|}
\hline & Average & Max & Min & Standard deviation & Median & Mode & Skewness & kurtosis \\
\hline $\mathrm{N}=1391$ & 45.93 & 91 & 16 & 13.21 & 44 & 41 & 0.628 & 0.022 \\
\hline
\end{tabular}


It is emphasized that Mode of 41 means the peak age of gaining great achievements in humanities \& social sciences. The result is confirmed with Beard's peak age 40 gained in 1874, on the contrary, the peak age in natural science is 37 years old (Liang Li-ming\&Zhao Hong-zhou 1991.

\subsection{Tests of fit for the distribution of achieve age in humanities \& social sciences}

From the result of above descriptive statistics we can know the empirical frequency distribution of humanities \& social achievements has a figure of positive-skewed, leptokurtosis and fat-tail. So we use SAS statistics software to conduct test of fit toward the data by the methods of normal distribution, exponential distribution, lognormal distribution and Welbull distribution; then choose the best one of fit effect. Fig. 1 for Fitting distribution, and table 3 shows the result of goodness of fit test.

\section{Frequency}

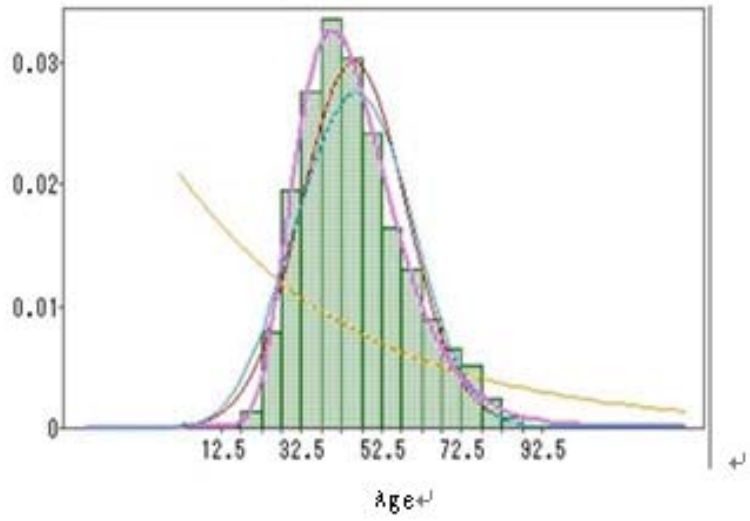

Fig. 1. Fitting distributions of talents' achievements in humanities and social sciences

Table 3. The result of goodness of fit test

\begin{tabular}{|c|c|c|c|c|c|c|}
\hline Curve & Theta & & Sigma & Zeta/c & Kolmogorov D & $\operatorname{Pr}>0$ \\
\hline Normal & & 5,3252 & 13.2147 & & 0.0755 & $<.01$ \\
\hline Lognormal & & 1) & 0.2870 & 3.7862 & 0.0234 & 0.08 \\
\hline Exponential & $0 \frac{1}{6}$ & I & 45.9252 & & 0.4076 & $<01$ \\
\hline Weibull & 0 䏡 & E & 50.8534 & 3.6615 & 0.0801 & $<.01$ \\
\hline
\end{tabular}

We can see all P-values under 0.05 in lognormal distribution, exponential distribution and Welbull distribution three test methods from table 3. So we should refuse the original assumption. In the table only P-value of the lognormal distribution 0.0652 is larger than 0.05 . This suggests the fit effect of lognormal distribution is better than the others, thus could use lognormal distribution to approximate the probability distribution functions of talents' achievements in humanities \& social sciences.

Probability density function of lognormal distribution is

$$
f(x)=\left\{\begin{array}{c}
\frac{1}{\sigma \sqrt{2 \pi}} e^{-\frac{(\ln x-\theta)^{2}}{2 \sigma^{2}}} \frac{1}{x}, \quad x>0, \\
0, \quad \text { otherwise, }
\end{array}\right.
$$


where $\theta$ is the mean, $\sigma$ is the standard variation. From the result of fitting test, we get that $\sigma=0.29, \quad \theta=3.79$.

The lognormal distribution is a life distribution model used widely in life test and a number of scholars have proved that life model is more suitable for describing life distribution. (2009) The observed data from the beginning to the occurrence is called life. Such as, expiry time of eclectic equipment, the occurring time of cancer and the time for scientists achieving masterpieces, etc. Though the life talked here is not a precise life, for the individual of some group the time from the beginning to the occurring is its real life. Its physical model as follows: supposing an occasional phenomena is caused by a series of independent normal occasional factors, the former signed as $\xi$, the latter signed as $\xi(\mathrm{n}-1,2 \ldots)$, the relationship between them is $\xi=\xi 1 \times \xi 2 \times \ldots$ Thus

$$
\log \xi=\sum_{\mathrm{n}} \log _{\mathrm{n}}
$$

If all $\log \xi_{\mathrm{n}}$ are small and independent, according to central limit theorem we know $\log \xi$ obeys normal distribution $N(\theta$ , $\left.\sigma^{2}\right)$. In turn, $\xi$ is the lognormal distribution. Let $\xi$ be the age of humanities and social scientists who gain great achievements. Then $F(x)=p(\xi<x)$ shows the probability of acquiring great achievement of humanities and social scientist whose age is smaller than $x$.

\section{Statistical description of achievement-age distribution in different periods of humanities and social sciences}

The development of the talent is affected by various internal and external factors. Simonton (Dean Keith Simonton 1975) pointed that external macroscopical environment: such as time spirit, political pattern, war, Civilization Conflict and political stability etc., makes an influence on innovations of talents. Cultural structure is one of the most influential factors for the development of talent. (Dean Keith Simonton 1996) Thus, each distribution of talents' achievement-age in different periods has its own characteristic.

\subsection{Statistics and fit of achievement-age distributions of talents in each century}

As showed in table 4 and Fig.2, the number of achievements in humanities \& social sciences increases gradually from $1400 \mathrm{~s}$ to 1990s. Among achievements distributions in these centuries, the group of 31-40 takes the most proportion of achievements in 16th, 18th and 19th century, but in 15th, 17th and 20th century $41-50$ group takes the most.

Table 4. The statistical data of achievement and age classified by century during 1400 - 1990

\begin{tabular}{|c|c|c|c|c|c|c|c|c|c|c|c|c|c|c|c|c|c|}
\hline \multirow{2}{*}{\begin{tabular}{|c|} 
age group \\
years \\
\end{tabular}} & \multicolumn{2}{|c|}{$\begin{array}{l}\text { Under } \\
\text { 20years } \\
\text { old }\end{array}$} & \multicolumn{2}{|c|}{$21-30$} & \multicolumn{2}{|c|}{$31-40$} & \multicolumn{2}{|c|}{$41-50$} & \multicolumn{2}{|c|}{$51-60$} & \multicolumn{2}{|c|}{$61-70$} & \multicolumn{2}{|c|}{$71-80$} & \multicolumn{2}{|c|}{$\begin{array}{c}\text { above } \\
\text { 80years } \\
\text { old }\end{array}$} & \multirow[t]{2}{*}{ total } \\
\hline & No. & $\%$ & No. & $\%$ & No. & $\%$ & No. & $\%$ & No. & $\%$ & No. & $\%$ & No. & $\%$ & No. & $\%$ & \\
\hline $1400-1500$ & & & 2 & 7.14 & 7 & 25 & 6 & 21.43 & 2 & 7.14 & 6 & 21.43 & 4 & 14.29 & 1 & 3.57 & 28 \\
\hline $1500-1600$ & & & 5 & 11.63 & 8 & 18.60 & 12 & 27.91 & 11 & 25.58 & 5 & 11.63 & 2 & 4.65 & & & 43 \\
\hline $1601-1700$ & & & 5 & 6.17 & 14 & 17.28 & 28 & 34.57 & 18 & 22.22 & 10 & 12.35 & 6 & 7.41 & & & 81 \\
\hline $1701-1800$ & 2 & 1.60 & 12 & 9.60 & 37 & 29.60 & 29 & 23.20 & 25 & 20.00 & 8 & 6.40 & 8 & 6.40 & 4 & 3.20 & 125 \\
\hline $1801-1900$ & 1 & 0.22 & 70 & 15.49 & 135 & 29.87 & 131 & 28.98 & 64 & 14.16 & 35 & 7.74 & 11 & 2.43 & 5 & 1.11 & 452 \\
\hline $1900-1990$ & 2 & 0.30 & 42 & 6.34 & 182 & 27.49 & 222 & 33.53 & 111 & 16.77 & 66 & 9.97 & 31 & 4.68 & 6 & 0.91 & 662 \\
\hline Totol & 5 & 0.36 & 136 & 9.78 & 383 & 27.53 & 428 & 30.77 & 231 & 16.61 & 130 & 9.35 & 62 & 4.46 & 16 & 1.15 & 1391 \\
\hline
\end{tabular}




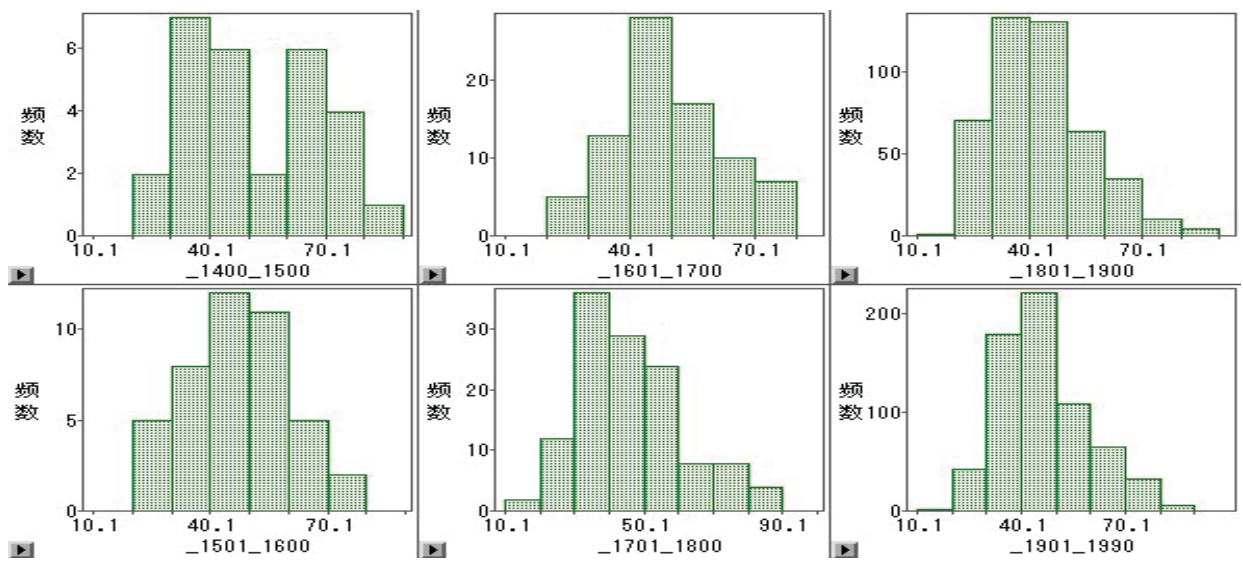

Fig.2. The histogram of achievement and age classified by century during 1400-1990

\subsubsection{Fit test of talents' achievements of humanities \& social sciences in $15^{\text {th }}$ century}

As showed in table 5 and Fig.3, taking fit test of great achievements of humanities \& social sciences in 15th century by lognormal distribution method, $P>0.15>0.05$ in the result of goodness of fit test. It shows great achievements distribution in 15 th century matches the lognormal distribution.

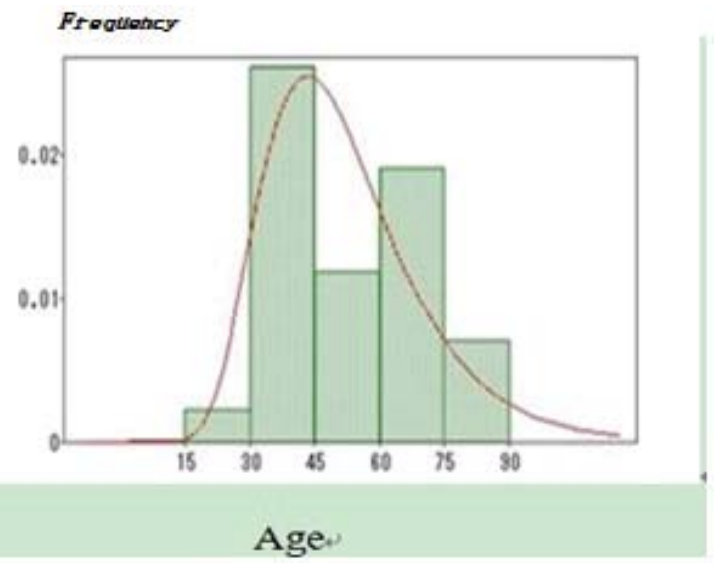

Fig.3. Fit distribution of achievements in $15^{\text {th }}$ century

Table 5. The result of goodness of fit of great achievements in $15^{\text {th }}$ century

\begin{tabular}{|c|c|c|c|c|c|c|}
\hline \multicolumn{7}{|c|}{ 分布检俭 } \\
\hline 曲线 & 分布 & 均值/Thet a & Sigma & Zeta/C & Kolmogorov D & $\mathrm{Pr}>\mathrm{D}$ \\
\hline & 对数正态 & $\square$ & 0.3418 & 3.8986 & 0.1410 & $>.15$ \\
\hline
\end{tabular}

\subsubsection{Fit test of talents' achievements of humanities \& social sciences in $16^{\text {th }}$ century}

As showed in table 6 and Fig4, taking fit test of great achievements of humanities \& social sciences in 16th century by lognormal distribution method, $\mathrm{P}>0.15>0.05$ in the result of goodness of fit test. It shows great achievements distribution in 16th century matches the lognormal distribution. 


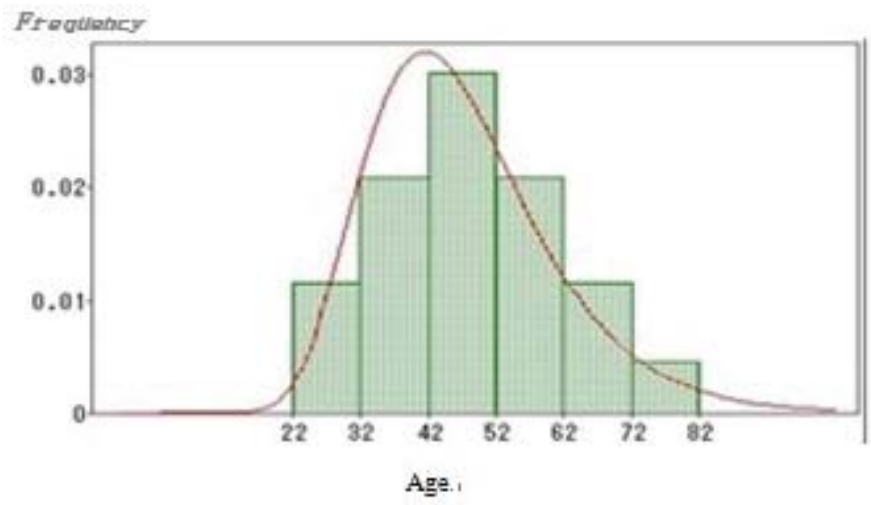

Fig .4. Fit distribution of achievements in $16^{\text {th }}$ century

Table 6. The result of goodness of fit of great achievements in $16^{\text {th }}$ century

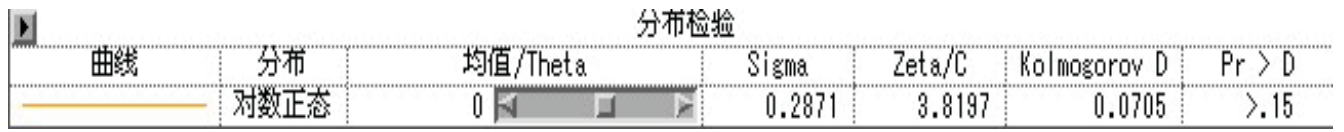

\subsubsection{Fit test of talents' achievements of humanities \& social sciences in $17^{\text {th }}$ century}

As showed in table 7 and Fig.5, taking fit test of great achievements of humanities \& social sciences in 17th century by lognormal distribution method, $P>0.15>0.05$ in the result of goodness of fit test. It shows great achievements distribution in 17 th century matches the lognormal distribution.

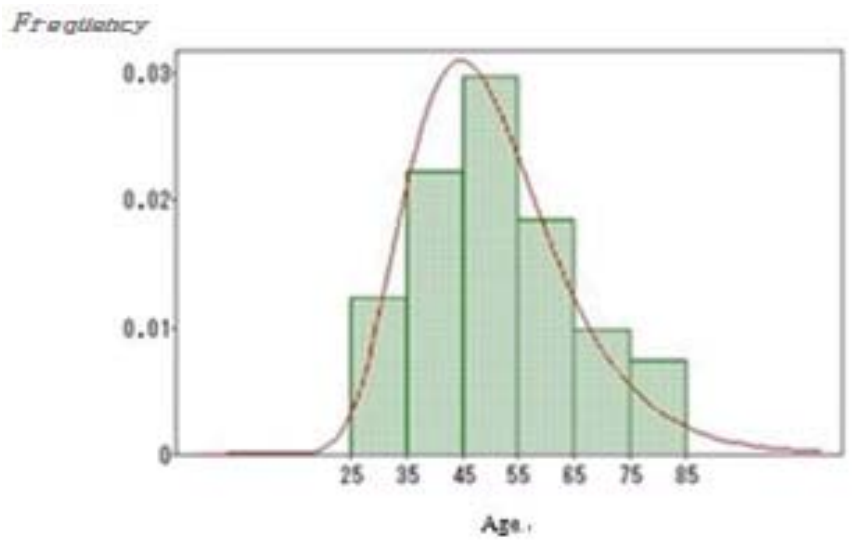

Fig.5. Fit distribution of achievements in $17^{\text {th }}$ century

Table 7. The result of goodness of fit of great achievements in $17^{\text {th }}$ century

\begin{tabular}{|c|c|c|c|c|c|c|}
\hline I & & 分布 & & & & \\
\hline 曲线 & 分布 & 均值/Theta & Sigma & Zeta/C & Kolmogorov D & $P r>D$ \\
\hline & 对数正态 & $0 \pi$ & 0.2753 & 3.8870 & 0.0518 & $>.15$ \\
\hline
\end{tabular}




\subsubsection{Fit test of talents' achievements of humanities \& social sciences in $18^{\text {th }}$ century}

Taking fit test of great achievements of humanities \& social sciences in 18th century by lognormal distribution method, $P>0.15>0.05$ in the result of goodness of fit test as showed in table 8 and Fig.6. It shows great achievements distribution in 18 th century matches the lognormal distribution.

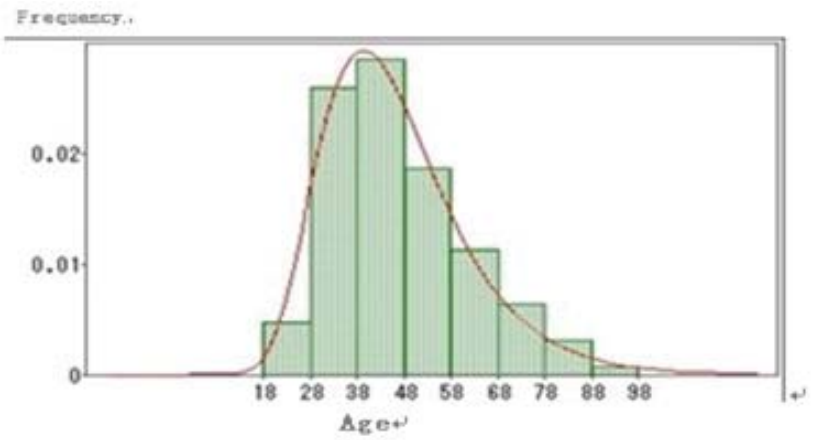

Fig. 6. Fit distribution of achievements in $18^{\text {th }}$ century

Table 8. the result of goodness of fit of great achievements in $18^{\text {th }}$ century

\begin{tabular}{|c|c|c|c|c|c|c|}
\hline \multicolumn{7}{|c|}{ 分布检检 } \\
\hline 曲线" & 贫市 & 玸值/Thet a & Sigma & Zeta/C & Kolmogorov D & $\mathrm{Pr}>\mathrm{D}$ \\
\hline & 对数正态 & $\bar{y}$ & 0.3251 & 3.7904 & 0.0446 & $>.15$ \\
\hline
\end{tabular}

\subsubsection{Fit test of talents' achievements of humanities \& social sciences in $19^{\text {th }}$ century}

As showed in table 9 and Fig.7 taking fit test of great achievements of humanities \& social sciences in 19th century by lognormal distribution method, $\mathrm{P}$ value $0.05<0.1031$ in the result of goodness of fit test. It shows great achievements distribution in 19th century matches the lognormal distribution.

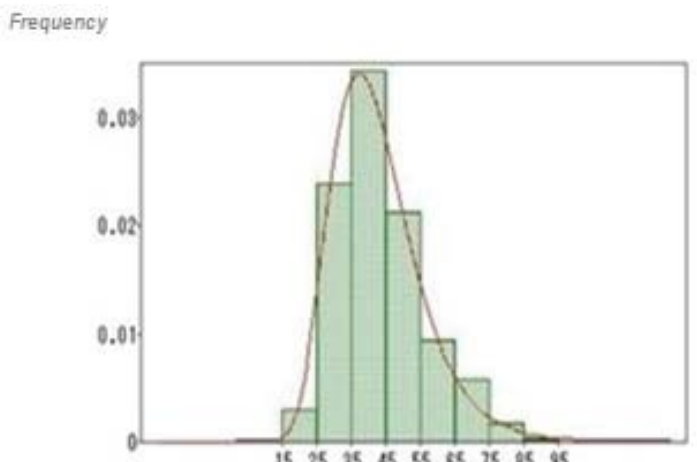

1525 25 45 S5 8575 is 95

Fig.7. Fit distribution of achievements in $19^{\text {th }}$ century

Table 9. The result of goodness of fit of great achievements in $19^{\text {th }}$ century

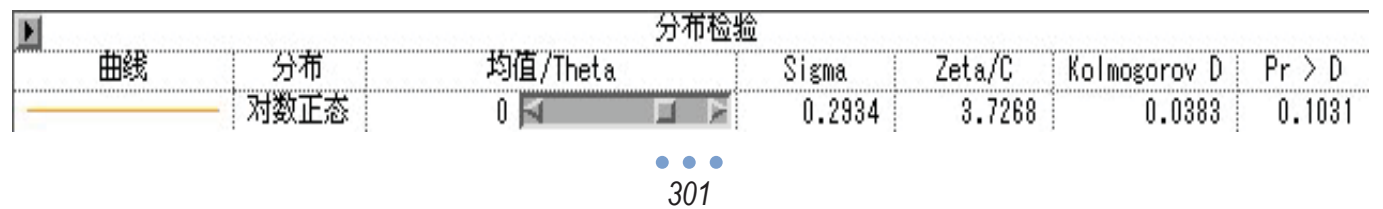




\subsubsection{Fit test of talents' achievements of humanities \& social sciences in $20^{\text {th }}$ century}

As showed in table 10 and Fig.8, taking fit test of great achievements of humanities \& social sciences in the first ninety years of 20th century by lognormal distribution method, gets a result $P$ value $0.1154>0.05$ in the goodness of fit test. The distribution shows great achievements distribution in 20th century matches the lognormal distribution.

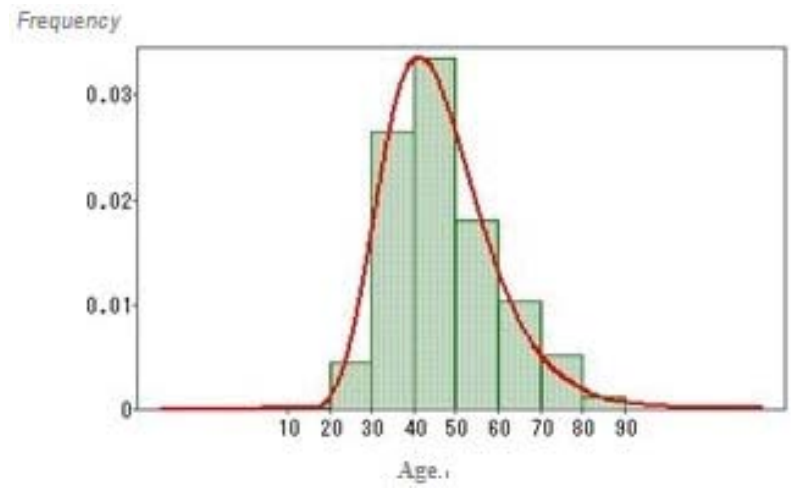

Fig.8. Fit distribution of achievements from 1901 to 1990

Table 10. The result of goodness of fit of great achievements during 1901-1990

\begin{tabular}{|c|c|c|c|c|c|c|c|}
\hline \multicolumn{8}{|c|}{ 分布检验 } \\
\hline 曲线 & 分希 & "均值 $/$ 丁 & & Sigma & Zeta/C & Kolmogorov D & $\mathrm{Pr}>\mathrm{D}$ \\
\hline- & 对数正态 & $0 \pi$ & $\pm x$ & 0.2707 & 3.8105 & 0.0313 & 0.1154 \\
\hline
\end{tabular}

As suggested above, all the great achievements between 1400s and 1990s show the lognormal distribution with subtle differences.

\subsection{The changing of peak in talents' achievement-age distribution}

The common distributions and different parameters show there is definite connection and change rule between great achievement and talent's age in humanities \& social sciences. In lognormal distribution, position parameter equals the Mean of random variable $\theta$ and scale parameter equals logarithmic standard deviation $\sigma$.

Table 11. Lognormal distribution and peak changing table of achievement-age in humanities and social sciences

\begin{tabular}{|c|c|c|c|c|c|c|}
\hline Century & $1400-1500$ & $1501-1600$ & $1601-1700$ & $1701-1800$ & $1801-1900$ & $1901-1990$ \\
\hline Peak age & 44.1 & 42.1 & 45.2 & 39.9 & 38.1 & 42.0 \\
\hline Peak age group & $41-50$ & $41-50$ & $41-50$ & $31-40$ & $31-40$ & $41-50$ \\
\hline Achievements percentage & $21 \%$ & $28 \%$ & $35 \%$ & $30 \%$ & $30 \%$ & $34 \%$ \\
\hline
\end{tabular}




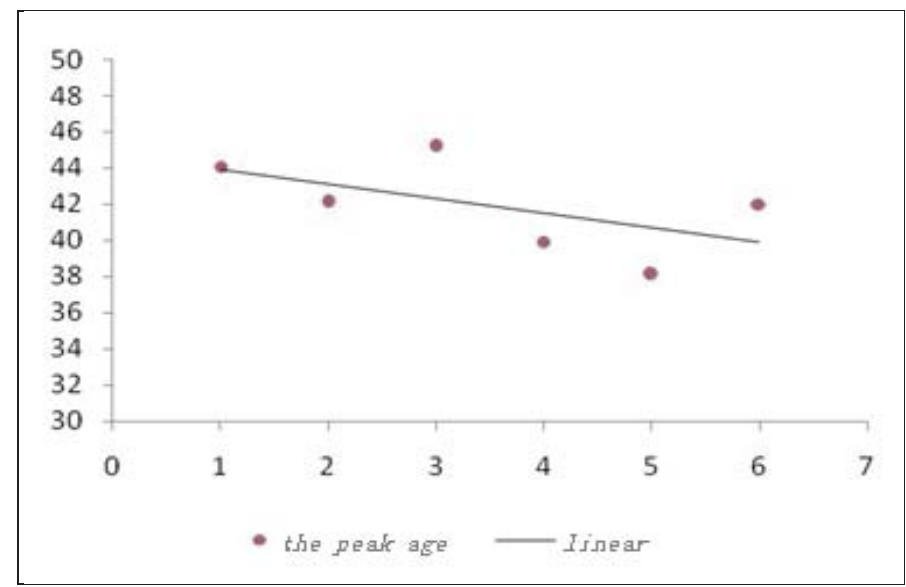

Fig.9. Great achievement peak age trend chart of humanities \& social sciences among 1400-1990

Table 11 and Fig.9 show the change rule about peak age which changes from 44.1 years old in 15 th century to 42 years old in 20th century. Though in 20th century rises over 18th \& 19th century's below 40, the whole linear trend decreases gradually. That is to say, the peak age on the whole has a forward trend among 1400-1990. Peak age moves forward quickly among 17th -18th century but slowdown among 18th-19th century. And age group of the peak corresponding achievement percentage increases from 21 percent in 15th century up to 34 percent in 20th century. This manifests the humanities and social scientists in the peak age group have made more and more contributions.

\section{Talent's productivity distribution in Humanities and Social sciences}

As the area below density function curve stands the probability of acquiring great achievement of humanities \& social scientists on corresponding age, then we can use the equation

$$
\int_{0}^{t} f(x) d x=\int_{t}^{\infty} f(x) d x
$$

to find the point which divides the area below density function curve equally. The point is the age boundary, age under or over the point takes half of the all great achievements respectively.

If $X \sim \operatorname{LN}(\theta, \sigma 2)$, then $\ln X \sim N(\theta, \sigma 2)$.. Furthermore, $\frac{\ln X-\theta}{\sigma} \sim N(0,1)$. Therefore $\frac{\ln X-\theta}{\sigma}=0$ the area below density function curve is divides equally. Therefore we can find the age boundary: $x=e \theta$. the age boundaries of different times are in the following Table.

Table 12. Age boundary on acquiring half of all great achievements in humanities \& social sciences

\begin{tabular}{|c|c|c|c|c|c|c|}
\hline $\begin{array}{c}\text { Time } \\
\text { (year) }\end{array}$ & $1400-1500$ & $1501-1600$ & $1601-1700$ & $1701-1800$ & $1801-1900$ & $1901-1990$ \\
\hline Age Boundary $(\mathrm{x})$ & 49.3 & 45.6 & 48.8 & 44.3 & 41.5 & 45.2 \\
\hline
\end{tabular}

Table 12 shows half of all great achievements are made by scientists under 50 years old in humanities \& social sciences from 15th century to 20th century. Actually the achievement productivity of the groups under 25 and over 75 years old is lower, only accounting for 1-2\%. The majority of achievements in humanities \& social sciences centralize in the group of $25-75$ and this group is called effective age group. The age span is 50 years old and the group of 25-50 is just half the span. Therefore, we can see the productivity of humanities \& social sciences has a balanced distribution and there is not the phenomenon of achievements centralizing in one age group. 


\section{Conclusion}

Through taking mathematical analysis and fit test against samples on the whole, we draw the conclusion that the age of talents acquiring great achievements in humanities \& social sciences match the rule of lognormal distribution and the peak age is 41 . It easily ignores the influences on talents' achievement-age from special circumstances in different times when analyzing the samples on the whole, so the paper further to take statistical analysis with achievement-age of talent from 1400 s to 1990 s separately. The analysis result manifests achievement-age distribution of each century in humanities \& social sciences matches the lognormal distribution and the peak age on the whole has a forward trend from $15^{\text {th }}$ century to $20^{\text {th }}$ century.

If making further analysis of talent's productivity in humanities and social science, we can find the age-group span is correspondent to the percentage of achievements accounting for the all. That is to say, the productivity of humanities \& social sciences has a balanced distribution and there is not the phenomenon of achievements centralizing in one age group.

\section{References}

Alan E. Bayer, Jeffrey E. Dutton. 1977 ."Career Age and Research-Professional Activities of Academic Scientists: Tests of Alternative." The Journal of Higher Education.48, 259-282

Allison, P.D., J.A.Stewart, 1974. "Productivity Differences among Scientists:Evidence for Accumulative Advantage."American Sociological Review.39, 596-606

A.M.Diamond. Jr, 1984. "An Economic Model of the Life-Cycle Research Productivity of Scientists. " Scientometrics. 6, 189-196

Cai Yan-hou, Feng Yong-jun and Wang Lin-feng,ect. 2009. "A Study on the Report of Chinese Outstanding Humanities and Social Scientists in 2008(Abstract )." China Higher Education Evaluation, 31-36

Clement,Frank. 1973. "Early Determinants of Research Productivity.American." Journal of Sociology. 79, 409-419

David W.Galenson, Bruce A.Weinberg. 2005."Creative Careers: The Life Cycles of Nobel Laureates in Economics".http://www.nber.org/papers/w11799.pdf? new_window=1.

Dean K.Simonton. 1977. "Creative Productivity, Age, and Stress: A Biographical Time-Series Analysis of 10 Classical Composers." Journal of Personality And Social Psychology.35, 791-804

Dean K.Simonton. 1989. "The Swan-Song Phenomenon: Last-Works Effects for 172 Classical Composers."Phycology and Aging. 4, $42-$ 47

Dean K. Simonton. 1991. "Creative Productivity through the Adult Years." Generations. 15, 13-16

Dean K.Simonton. 1977. "Creative Productivity, Age, and Stress:A Biographical Time-Series Analysis of 10 Classical Composers. "Journal of Personality And Social Psychology. 35, 791-804

Dean K.Simonton. 1988. "Age And Outstanding Achievement: What Do We Know after A Century Of Research? "Psychological Bulletin. 104, 251-267

Dean Keith Simonton. 1975. "Sociocultural Context of Individual Creativity: A Transhistorical Time-Series Analysis. "Journal of Personality and Social Psychology.32, 1119-1133.

Dean Keith Simonton. 1996. "Individual Genius within Cultural Configurations :The Case of Japanese Civilization." Journal of CrossCultural Phycology. 354-375

Encyclopedia of China Publishing House ed, 1985. Concise Encyclopedia Britannica.. China,.chap.6,P. I

Elaine.A. Lally.2001. "Researcher's Perspective on Electronic Scholarly Communication." Online Information Review .25, 80-87

F.barron,D.Harrington. 1981. "Cteativity, Intelligence, And Personality."Annual Reviers Of Psychology. 32 , $439-476$

George M. Beard. 1874.Legal Responsibility in Old Age. Russells, New York, P.5-42

George M. Beard. 1881.American Nervousness, Its Causes and Consequences, G. P. Putnam's sons,ed New York

Harvey C. Lehman. "Age and Achievement", in Harry R.Moody, Aging-Concepts and Controversies, California: Pine Forge Press, 1994, P. 372-377.

Hendrik P.Van Dalen. 1999. "The Golden Age of Nobel Economists."American Economist.43, 19-35

Jin Sheng-hua, Zhang Jing-huan and Wang Jing. 2010. "A Study on the Characteristics of Innovative Talents and Its Enlightenment to Education. "Journal of The Chinese Society of Education, 5-10

Joshua Guetzkow, Michele Lamont. 2004. "What is Originality in the Humanities and the Social Sciences?." American Sociological Review,69, 190-212

Liang Li-ming, Zhao Hong-zhou , 1991. "The Age of Scientific Discovery Is Weibull Distribution. "Journal of Dialectics of Nature, 28-36

Liang Li-ming, Wang Yuan, Ding Fan,ect . 1999. "New Development of Age Distribution Study about Science and Culture Achievements." Journal of Dialectics of Nature. 21, 28-33

Mcdowell John. 1982. "Obsolescence of Knowledge and Careerand Coauthorship Profiles." American Economic Review. $72,752-768$.

M. Mahapatra,S C. Biswas. 1985. "Concept Specification by PRECIS Role Operators: Some Technical Problems with Social Science and Humanities Literature. "Library and Information Science Research. 7, 53-73

Maliha Nasir, Rehana Masrur. 2010. "An Exploration of Emotional Intelligence of the Students of IIUI in Relation to Gender,Age and 
Academic Achievement."Bulletin of Education and Research,31, 37-51

Merton,Robert K. 1988. "The Matthew Effect in Science, II Cumulative Advantage and the Symbolism ofIntellectual Property".ISIS,79, $607,606,618,618,619,619$

Nicolas Carayol,Mireille Matt. 2006. "Individual and Collective Determinantsof Academic Scientists' Productivity."Information Economics And Policy. 18, 55-72

Ou Yang-kang.2004.Philosophy of Humanities-Social Sciences.Wu Han:wuhan university , 18-120

Richard W.Slatta.1986. "Telecommunications for the Humanities and Social Science.Microcomputers for Information Manangement:An International. "Journal for Library and Information Services.3, 91-110

Richard A.Wanner, Lionel S.Lewis and Dawid I. Gregorio. 1982. "Productivity in Academia:A Comparative Study of the Sciences,Social Sciences and Humanities." Sociology of Education.54, 238-253

Stephen Cole. 1979. "Age and Scientific Performance."American Journal of Sociology. 84,958-977

Sharon M. Oster , Daniel S. Hamermesh. 1998. "Aging and Productivity among Economists."The Review of Economics and Statistics. 80, 154-156

Svein Kyvik, 1990. "Age and Scientific Productivity. Differences between Fields of Learning. "Higher Education.19, 37-55

Svein Kyvik, Terje Bruen Olsen. 2008. "Does the Aging of Tenured Academic Staff Affect the Research Performance of Universities?" Scientometrics.76, 439-455

Thomas H. Goodwin.1995." Life Cycle Productivity in Academic Research: Evidence from Cumulative Publication Histories of Academic Economists." Southern Economic Journal.61, 728-743.

Wu Peng-sen,Fang Lie-shu. 2011. Basic Sociology. Shang Hai, P. 9-1

Wang Jian, 2003 "A Report on the Humanities and Social Sciences Outstanding Achievement Award of Shanghai." Social Outlook, 3435.

Yuan Xi-lin . 2011. "Research on Discipline System of Social Science \& Humanities."Nanjing University, 38-40

Zhou Da-ya. 2004. "The Age Distribution Study about The Masters in Chinese Academy of Social Sciences." Management and Review of Social Sciences, 8,41-47

Zhou Feng-lin. 2009. "Statistical Diagnostics for the Log-normal Distribution Regression Model . "GuiZhou University of Finance and Economics. 13-55

Zuckerman, Harriet. 1988. Sociology of Science: Handbook of Sociology,.Newbury Park ed .Calif.Sage Publications, p.531,527. 